\title{
Metamorfosis de lo moderno: el Greco en la poesía de entresiglos
}

\author{
Rafael Alarcón Sierra \\ Universidad de Jaén
}

Título: Metamorfosis de lo moderno: el Greco en la poesía de entresiglos.

Resumen: El presente artículo analiza la presencia del Greco en la literatura hispánica de entresiglos y, más concretamente, en la poesía modernista. Su aportación más característica es el poema breve que realiza una écfrasis de un retrato del Greco, siguiendo, con mayor o menor fidelidad la manera parnasiana. El óleo casi siempre representado es El caballero de la mano al pecho. En segundo lugar, otro tipo de poema es el que trata de sugerir el misterio de la ciudad de Toledo, donde El Greco aparece como ingrediente indispensable. Otras apariciones del pintor son su empleo comparativo o su consideración como elemento decadente y grotesco, característico de una "España negra".

Palabras clave: El Greco, El caballero de la mano al pecho, modernismo, poesía, "España negra".

Fecha de recepción: 16/7/2015.

Fecha de aceptación: 31/10/2015.
Title: Metamorphosis of the Modern: the Greco in the Poetry between Ages.

Abstract: This paper analyses the presence of El Greco in Hispanic literature at the turn of the century and, in particular, in the modernist poetry. Its most distinctive contribution is a type of short poem that makes an ekphrasis of a portrait by El Greco and follows, more or less accurately, the Parnassian manner. The most represented painting is El caballero de la mano al pecho. Secondly, other poems try to suggest the mystery of the city of Toledo, where El Greco appears as an essential element. Other appearances of the painter include being used as a comparative or its conception as a decadent and grotesque characteristic of "la España negra".

Key words: El Greco, El caballero de la mano al pecho, modernism, poetry, "España negra”.

Date of Receipt: 16/7/2015.

Date of Approval: 31/10/2015. 


\section{INTRODUCCIÓN}

El Greco, cuyo cuarto centenario hemos celebrado en 2014, es nuestro contemporáneo. Es un fecundo anacronismo moderno, una creación de la primera mitad del siglo XX. Es entonces cuando tiene lugar la extraña $y$ peregrina historia de cómo un oscuro pintor que nace en Creta y recorre Europa de un extremo a otro, de oriente a occidente (Venecia, Roma, Toledo), que durante su vida es contemplado como un pintor extravagante y solitario que no obtiene demasiado reconocimiento, acaba siendo considerado el iniciador de la escuela de pintura española, un genio indiscutible y un antecedente de los primeros movimientos de vanguardia. Es un viaje que va del presente al origen, y la última etapa de un proceso en el que, en primer lugar, Goya es "descubierto" por los románticos; luego, Velázquez es considerado un maestro por el naturalismo y el impresionismo y, finalmente, el Greco es visto como un precedente de simbolistas, modernistas, cubistas, futuristas o expresionistas (y, como sucede con los anteriores, fuente inagotable de inspiración y estudio) ${ }^{1}$.

El Greco recibió, en la hora de su muerte, sonetos laudatorios de Paravicino (quien ya le había dedicado previamente otros cuatro), Góngora y Cristóbal de Mesa. Esta coincidencia estética, que destacaba tanto su singularidad como su fondo intelectual, volveremos a encontrarla en el momento de recuperación del pintor cretense. En cuanto se impusieron los principios naturalistas en la pintura española, su singularidad fue vista como extravagancia, juicio que se extiende en la segunda mitad del siglo XVII y perdura hasta las primeras décadas del XIX².

Las ideas románticas transformaron esta supuesta "extravagancia" en la "locura del genio". A ello contribuyó la apertura de la Galería Española de Luis Felipe en 1838, en donde había nueve obras del Greco, las cuales despertaron la admiración de diversos escritores franceses, hasta el punto

1 Véase Rafael Alarcón Sierra, Vértice de llama. El Greco en la literatura hispánica (Estudio y antología poética), Valladolid, Universidad de Valladolid, 2014.

2 Véase José Álvarez Lopera, De Ceán a Cossío: la fortuna crítica del Greco en el siglo XIX. El Greco: textos, documentos y bibliografía, Madrid, Fundación Universitaria Española, 1987, II, así como Eric Storm, El descubrimiento del Greco. Nacionalismo y arte moderno (1860-1914), Madrid, Marcial Pons / Centro de Estudios Europa Hispánica, 2011. 
de hacer del cretense una sublime figura romántica. Gautier se convirtió en el máximo responsable de la nueva imagen del Greco con sus comentarios en su Viaje a España (1840), donde anota que en sus obras reina "una energía depravada, una potencia enfermiza, que delatan al gran pintor y al loco genial", y lo compara con Delacroix ${ }^{3}$.

En España, fueron los viajeros extranjeros los que empezaron a descubrir el valor del Greco. Larra o Bécquer lo citan, el primero en el Voyage en Espagne del barón Taylor (1826-1860, III vols.), y el segundo en el tomo sobre Toledo de la Historia de los templos de España (1857), aunque sin aportar nada significativamente personal. El cambio de orientación se origina en el proceso de exaltación nacionalista de la "escuela española" que se desarrolla a lo largo del siglo XIX, donde el Greco será considerado, por críticos e historiadores (Enrique Mélida, Modesto de Castro, Ceferino Araujo, Pedro de Madrazo), fundador y antecedente de Velázquez.

Por otra parte, los pintores de avanzada se interesan cada vez más por su obra y por sus técnicas; en el círculo de Manet, el Greco comienza a ser considerado un pintor "de culto", lo que es motivo para adquirir sus obras. El cretense será visto como un modelo en el simbolismo, el impresionismo, el cubismo y el expresionismo; a su vez, la pintura moderna posibilita otra visión e interpretación de su obra.

Los escritores decadentes convierten al Greco en uno de sus pintores fetiches. No hará falta más que referirse a la Biblia negra del movimiento decadentista, $A$ rebours (1884) de Huysmans. El protagonista de la novela convierte su dormitorio en una especie de "celda monacal" que está presidida por un Cristo del Greco, pintura que califica de "siniestra, de tonos oscuros y de un verde cadavérico" . Jean Lorrain, en su novela Monsieur de Bougrelon (1897), acrecienta esta caracterización decadentista y negra del pintor.

La plena recuperación del Greco ocurre en España en el fin de siglo, cuando escritores y artistas buscan redefinir la modernidad artística y las señas de identidad nacionales. Sobresale el papel jugado por Santiago Rusiñol e Ignacio Zuloaga. Rusiñol transfiere su interés por el Greco a

3 Théophile Gautier, Voyage en Espagne, París, Charpentier Libraire Éditeur, 1858, pp. 172 y 40, respectivamente. La traducción es mía.

4 Joris-Karl Huysmans, À rebours, ed. Marc Fumaroli, París, Gallimard, 1977, pp. 155-156. La traducción es mía. 
sus amigos simbolistas belgas, como Verhaeren o van Rysselberghe, y lo convierte en un pintor místico y simbolista. Zuloaga se convierte en su embajador mundial, y es el responsable del interés por el cretense de Rainer María Rilke y de Maurice Barrès, o de que Picasso tenga en cuenta la Visión del Apocalipsis a la hora de pintar Les demoiselles d'Avignon. El interés por el candiota también alcanza a pintores como Julio Romero de Torres y José Gutiérrez Solana.

Zuloaga juega un papel clave para que Rusiñol pueda adquirir los dos cuadros del Greco que poseía el financiero Pau Bosch, una Magdalena y un San Pedro. La llegada de ambas pinturas a Sitges el 4 de noviembre de 1894 fue un acto colectivo del modernismo catalán. Poco después, Rusiñol concibe el proyecto de levantar en Sitges un monumento al cretense por suscripción popular. El 24 de agosto de 1897 se celebró la colocación de la primera piedra y un año después se inauguró el monumento, obra de Josep Raynés.

En Madrid, la visión institucionista del Greco es fundamental para su consideración más extendida: un pintor que supo plasmar el espíritu castellano del paisaje, el alma y el misticismo español, ideas que difunden Francisco Giner de los Ríos y Manuel Bartolomé Cossío desde 1885. Con este planteamiento, que hace del Greco un importante valor del nacionalismo liberal, se relacionan los escritos de Pérez Galdós, Aureliano de Beruete, Martín Rico, Francisco Alcántara o Francisco Navarro Ledesma.

Los modernistas, encabezados por Pío Baroja y Azorín, construyen la visión del cretense como enigmático pintor simbolista, unido a un difuso anhelo de espiritualidad y a la reinvención de Toledo como el mejor tópico hispano de la "ciudad muerta", siguiendo la estela de Georges Rodenbach en Bruges-la-Morte (1892) o de Maurice Barrès en Du sang, de la volupté et de la mort (1894), donde ya aparece Toledo como un "lugar fantasmático", propicio para los anhelos de las almas atormentadas. Lo que en un primer momento se muestra en línea con la visión del decadentismo, luego se afirma en la dirección institucionista, que culmina con la monografía de Cossío El Greco (1908), donde este aparece como intérprete de la naturaleza, la vida, el alma y la nación españolas, amén de como primer pintor de su escuela y precedente de Velázquez.

El viaje a Toledo de Baroja y Azorín a finales de 1900 tiene una importancia crucial para los derroteros del Greco en la literatura espańola. Las 
impresiones del mismo quedaron recogidas en varios textos: en el único número de la publicación Mercurio (marzo de 1901) y las novelas Camino de perfección de Baroja más Diario de un enfermo y La voluntad de Azorín (ambas de 1902), amén de en varios artículos periodísticos.

Antes del viaje a Toledo, Baroja había publicado en el diario madrileño El Globo tres artículos sobre el cretense, los cuales contienen las ideas fundamentales de los modernistas sobre el pintor: un idealista exaltado que pinta la esencia y la vida contemplativa, así como la espiritualidad atormentada y las tensiones hacia el absoluto, fundiéndose con el paisaje castellano. Parece que es Baroja el primero que denomina a uno de estos anónimos retratos "El caballero de la mano en el pecho" (con la importancia que esto conlleva para su "lectura"), iniciando su conversión en icono cultural ${ }^{5}$.

Ambos escritores están abriendo un camino y proponiendo un nuevo canon, literario y pictórico, que acabará triunfando. Tanto Baroja como Azorín tienen en sus despachos reproducciones de cuadros del Greco -especialmente El caballero de la mano al pecho-, como hará buena parte de la intelectualidad española (empezando por Ortega y Gasset: léase el inicio de su conocida "Meditación del marco"), lo que implica tanto un patronazgo espiritual como una nueva manera de ver e interpretar al Greco. Es Azorín quien, a partir de la segunda década del siglo (tras la lectura de Cossío), desequilibra la balanza entre decadencia, mística e intrahistoria en el Greco a favor del último término: sus personajes representan una serena hidalguía que sintetiza el ser nacional. Conocida es también su formulación de 1913 sobre "La generación de 1898", donde no olvida resaltar el fervor por el pintor 6 .

En 1908 se publica la monografía de Manuel Bartolomé Cossío, El Greco, que culmina un trabajo iniciado décadas antes, y que sanciona y cristaliza definitivamente una imagen del pintor, en línea con la desarrollada desde finales del siglo XIX, de la que van a beber críticos, his-

5 Véase Pío Baroja, "Cuadros del Greco. I. Los retratos del Museo del Prado", El Globo, 26 de junio de 1900, p. 1; "Cuadros del Greco. II. Asuntos religiosos del Museo del Prado", ibidem (1 de julio de 1900), p. 2; "Cuadros del Greco. Tierra Castellana. En Santo Tomé”, ibidem (9 de julio de 1900), p. 2.

6 Azorín, "La generación de 1898", en Clásicos y modernos, Obras escogidas, II. Ensayos, Madrid, Espasa-Calpe, 1998, pp. 983-1000 (para el Greco, p. 999). 
toriadores y escritores a lo largo de todo el siglo XX. Tras la monografía de Cossío, la bibliografía del Greco se dispara, encabezada por los libros de Julius Meier-Graefe (Viaje a España) y de Maurice Barrès (El Greco o el secreto de Toledo). Hitos posteriores en España serán Poussin y El Greco (1922) de Eugenio d'Ors, El Greco (El visionario de la pintura) (1933), de Ramón Gómez de la Serna, o Elogio y nostalgia de Toledo (1940), de Gregorio Marañón.

\section{El Greco en la poesía modernista}

La presencia del Greco en la lírica es deudora de las interpretaciones que acabamos de ver. Su aportación más característica es el poema breve, preferentemente un soneto, que realiza una écfrasis de un retrato del Greco, siguiendo, con mayor o menor fidelidad, la manera parnasiana, realizando una transposición del cuadro al poema de forma aparentemente impersonal y rigurosa, en pos de un esteticismo culto y la perfección de la forma. En este caso, el óleo más representado es El caballero de la mano al pecho, que se convierte en España en un icono a la misma altura que La Gioconda o El nacimiento de Venus. En segundo lugar, otro tipo de poema es el que trata de sugerir el misterio de la ciudad de Toledo, donde El Greco aparece como un ingrediente indispensable. Otras apariciones del pintor en la poesía modernista son su mero empleo comparativo o su consideración como elemento decadente y grotesco, característico de una "España negra”. Salvo en este último caso, los retratos del pintor son interpretados como representantes de la hidalguía castellana. Y este valor perdura incluso en la segunda mitad del siglo XX, en los poemas que dedican al hidalgo autores como Vicente Aleixandre o León Felipe. Solo Rafael Alberti, Luis Cernuda, Pablo García Baena, Diego Jesús Jiménez o José Luis Rey, por citar algunos ejemplos sobresalientes, tratarán de hacer otra cosa, intentando trasponer líricamente los valores plásticos del Greco o, en el caso de Cernuda, estableciendo un diálogo elegíaco a través del espacio, el tiempo y el exilio con el retrato que el Greco hizo de Paravicino.

Rafael Cansinos Assens, con su habitual pericia, señala bien la presencia de esta corriente lírica en las primeras décadas del siglo XX, que califica de castellanista: 
Como orientación literaria, su influjo es enorme en todos los escritores del momento, que están todos más o menos tocados de las predilecciones arcaicas en el ambiente y el lenguaje. Por la atracción del arcipreste, o de Santa Teresa, o del Greco, el pintor de los caballeros castellanos, todos, aun los que parecen más orientados hacia lo exótico, son castellanistas. ¿En qué libro de versos contemporáneos no encontramos la oda a Castilla y la loa al Greco? Es la época del Greco, de las peregrinaciones artísticas a Toledo, del culto al Greco y a Toledo, que los poetas cantan y los críticos, como Azorín, estudian en todas sus categorías estéticas y metafísicas. [...] Para uno son los héroes; para otros, los místicos; para otros, el caballero de la mano al pecho; pero todos van allá como a un Santo Sepulcro, en ávida solicitud de inspiraciones [...] Sus símbolos plásticos son las figuras del Greco, secas, rígidas y contorsionadas, no por un báquico anhelo de danza, sino por un afán de éxtasis más perfecto ${ }^{7}$.

No obstante, la primera mención al Greco que encuentro en la poesía finisecular es previa a las interpretaciones de Azorín y Baroja. Salvador Rueda, en su poema "La paleta”, publicado en 1895, lo cita junto a Miguel Ángel, Velázquez, Murillo, Rosales y Fortuny, lo que, en esa fecha, todavía no es habitual (no lo hace, por ejemplo, Unamuno en su ensayo En torno al casticismo, donde sí cita a Velázquez, Murillo o Ribera como esencia de lo español). La composición, por lo demás, es típica de la poesía posromántica y premodernista, en que los pintores citados en una terna enumerativa, como elemento de prestigio cultural, son caracterizados de forma breve, tópica y convencional ${ }^{8}$.

En cuanto a los poemas que describen un retrato pictórico con moldes más o menos parnasianos, de forma aparentemente impersonal y objetiva, es conocida su genealogía y los mecanismos de este proceso de écfrasis (traducción de una forma visual, plástica, espacial, de percepción simultá-

7 Rafael Cansinos Assens, La nueva literatura. II. Las escuelas (1898-1900-1918). Colección de estudios críticos, Madrid, Editorial Páez, 1925, pp. 149-151.

8 Salvador Rueda, "La Paleta (Con motivo del baile del Círculo de Bellas Artes)", $L a$ Gran Via, 87 (24 de febrero de 1895). José Álvarez Lopera, op. cit., p. 521, señala una publicación posterior en Álbum Salón, III, 43, Barcelona (1 de junio de 1899), p. 136. 
nea, en una forma verbal, escrita, temporal, de lectura sucesiva), alentado por prerrafaelitas, parnasianos y simbolistas en su idea esteticista de unión de las artes ${ }^{9}$. Este tipo de poema es frecuente en el modernismo hispánico, hasta el punto de constituir un subgénero lírico. El "Felipe IV" de Manuel Machado, publicado en 1901, es uno de los modelos más tempranos y consistentes. Sin embargo, el primer poema-retrato dedicado al Greco quizá sea "El inquisidor", de Antonio de Zayas, único soneto dedicado al candiota (frente a los trece dedicados a Velázquez, por ejemplo) de los incluidos en Retratos antiguos, libro de 1902 que constituye un repertorio de este tipo de poemas. Manuel Machado, en su reseña del poemario, caracteriza estas composiciones por una aparente ausencia del sujeto lírico, una naturaleza estática y la pasividad del receptor, que se limita a admirar la quietud o serenidad del resultado ${ }^{10}$.

Tras Zayas (quien volvería a dedicar cuatro sonetos al pintor en la $\mathrm{Se}$ gunda serie de sus Epinicios, 1926), Villaespesa se imagina en "Alma española” (El jardin de las quimeras, 1909) viviendo en pleno Siglo de Oro, donde es retratado por el candiota y, poco después, encontramos el más famoso de los poemas dedicados al Greco: "El caballero de la mano al pecho" de Manuel Machado, perteneciente a un volumen lírico dedicado a describir pinturas, Apolo. Teatro pictórico, de 1911, y otras composiciones dedicadas al mismo retrato, en la estela del anterior: las de Francisco Maldonado y Fernando López Martín, en torno al tricentenario del Greco, y, algo más tardíamente, la de Fernando Iglesias Figueroa. Al otro lado del Atlántico sobresalen los sonetos de Álvaro Melián Lafinur y de Guillermo Valencia. Por otra parte, es objeto de discusión si la "Fantasía iconográfica" de Antonio Machado, inserta en Campos de Castilla y publicada en 1908 con el título de "Retrato", se refiere o no al Retrato del cardenal Tavera del Greco. También consagrado al caballero de la mano al pecho encontramos "El caballero de la espada. Cuadro del Greco", larga tirada

9 Véase Rafael Alarcón Sierra, Entre el modernismo y la modernidad: la poesía de Manuel Machado (Alma y Caprichos), Sevilla, Diputación Provincial de Sevilla, 1999, pp. 216-247.

10 Manuel Machado, “"Retratos antiguos» por Antonio de Zayas”, El Liberal [Sevilla], Edición de la mañana, II, 691 (27 de noviembre de 1902), p. 1. Véase Manuel Machado, Impresiones. El modernismo (Artículos, crónicas y reseñas, 1899-1909), ed. Rafael Alarcón Sierra, Valencia, Editorial Pre-Textos, 2000, pp. 108-111 y 313-319. 
de serventesios alejandrinos que Sofía Casanova incluyó en El cancionero de la dicha (1911). Esther López Valencia se aparta de esta tendencia con "El peregrino de amor", escrito "Ante el San Francisco de El Greco" e incluido en su poemario Escorial (1922), que cambia de estímulo visual, aunque no lo describe.

Salvo la última, estas composiciones tienen una serie de notas comunes. En primer lugar, todas son muy parecidas, no solo porque describan la misma pintura, sino porque el hecho de que partan de las mismas convenciones literarias y estéticas hace que su lectura del cuadro sea muy similar. En segundo lugar, la interpretación del poeta se sobrepone a la mera descripción de la obra plástica (algo que suele ocurrir en todo proceso de écfrasis). Y, obviamente, esta interpretación dice más del escritor que del pintor; reproduce la mentalidad, la ideología artística y el estado de ánimo del autor del texto y de su momento histórico, puesto que es una proyección suya sobre la pintura.

En tercer lugar, al ser el cuadro descrito el retrato de un individuo, prácticamente desaparece la pintura del Greco: el poema retrata más al personaje que a la pintura del mismo. De esta forma, se presenta de forma simplificada una compleja experiencia estética de transcodificación metarreflexiva, donde una obra artística desemboca en la creación de otra, autónomas pero relacionadas dialógicamente (creación de la pintura; observación de la misma; creación del poema; lectura del mismo... y vuelta a empezar, porque cada paso modifica los anteriores: el cuadro es leído y la imagen es sustituida). Lo que predomina en estas composiciones no son las alusiones a la técnica pictórica del Greco, sino la tentativa de construir un retrato textual del personaje previamente pintado, que combina en distintas proporciones la prosopografía y la etopeya, una suma de cualidades físicas y morales del individuo representado que, a su vez, proyectan una doble visión de la sociedad de su tiempo: de la del personaje sobre la del poeta, y viceversa. El hecho de tratarse de un personaje desconocido acentúa su misterio y el valor interpretativo de los textos que, sin embargo, en todos los poetas es similar. Finalmente, se trata de composiciones laudatorias y encomiásticas, que rinden tributo a una obra de arte (el cuadro) que se desdobla en otra obra de arte (el poema), y a un personaje doblemente representado, que acaba siendo símbolo de un pasado histórico y de una identidad nacional todavía orgullosa en el presente. 
Este corpus textual muestra la escasa variedad que posee la poesía modernista interesada por el Greco: cuando se decide a describir alguna de sus pinturas, casi siempre escoge su retrato más famoso (el cual, por ende, entra dentro de los cánones "realistas”). Ningún modernista tuvo el atrevimiento de Rainer Maria Rilke, que, en enero de 1913, durante su estancia en Ronda, escribió un sugerente poema, "Asunción de María”, basado en el retablo tardío del Greco que había visto poco antes en Toledo (hoy en el Museo de Santa Cruz), describiendo su armonía y su movimiento ascendente, y percibiendo un misterio que no era posible descifrar en la tierra. Está clara la dificultad de describir en un poema breve El entierro del conde de Orgaz, lo que sí hicieron en prosa Baroja o Barrès, por ejemplo. Pero ni siquiera hay variación en cuanto al retrato elegido. En realidad, esto nos indica que el conocimiento de la pintura del Greco a comienzos de siglo es escaso, salvo en lo referente a los dos cuadros citados, que se convierten en iconos culturales para una elite intelectual, y que son reproducidos fotográficamente. Por otra parte, parece que el interés es mayor por el anónimo y misterioso caballero de la mano en el pecho (supuesto símbolo del alma española) que por su padre artístico. No es frecuente encontrar poemas en los que el Greco aparezca como ejemplo de solitario, visionario y arrogante creador equiparable al modernista, tal y como lo describía, por ejemplo, Santiago Rusiñol.

El retrato de El caballero de la mano al pecho tiene tres puntos de interés: el rostro, la mano y la empuñadura de la espada, que no faltan en ninguno de los poemas que a él se dedican. Sin embargo, un cuarto elemento de la pintura, que sirve de nexo a los anteriores, la negra vestidura del personaje, no aparece en todos los casos. El medallón medio oculto y la cadena que cruza la ropilla son elementos secundarios que solo he encontrado en un poema. Curiosamente, de los cuatro elementos básicos en el retrato del Greco, salvo la espada, todos aparecen en el "Felipe IV" de Manuel Machado, que puede ser entendido como guía para este tipo de poemas, quizá incluso con más importancia que el cuadro mismo para el resultado lírico.

"El inquisidor", de Antonio de Zayas, aparece en su libro de 1902, Retratos antiguos ${ }^{11}$. Es el momento en que Baroja y Azorín están rede-

11 Antonio de Zayas, "Domenico Theotocópuli. El inquisidor", en Retratos Antiguos, Madrid, Establecimiento Tipográfico de A. Marzo, 1902, p. 83. 
finiendo al Greco, y en la misma composición se aprecia que el pintor todavía no tiene la popularidad que alcanzará poco después. Es cierto que el Greco pintó un retrato del Inquisidor General Fernando Niño de Guevara, pero no es este el cuadro que Zayas describe. Una vez repasado el repertorio de las pinturas del Greco o a él atribuidas, se observa que el retrato que más se asemeja al de Zayas es precisamente El caballero de la mano al pecho. Zayas parece imaginar que este caballero es un inquisidor. El título del poema también hace referencia a la acción de inquirir, que Zayas proyecta en la mirada del personaje, como bien reflejan sus dos primeros versos. Es posible que Zayas solo tuviera en la memoria el cuadro en el momento de componer el soneto, porque El caballero de la mano al pecho no empuña con la siniestra la "espada que del cinto pende", a no ser que imaginemos que lo hace fuera del cuadro y por debajo de la empuñadura; pero tampoco lo hace ningún otro personaje retratado por el Greco. Lo que estoy diciendo tiene sentido si damos por hecho que Zayas no se equivoca de pintor y que su propósito es describir fielmente un retrato del Greco; pero también caben otras opciones, porque el poeta puede realizar una écfrasis imaginaria, e incluso puede unir elementos de diversas pinturas, como había hecho Manuel Machado al fusionar en su poema "Felipe IV" dos retratos velazqueños, el del rey y el de su hermano el infante don Carlos.

Sea como fuere, el soneto de Zayas destaca por ser el que ofrece una descripción física más detallada del personaje (lo cual es lógico si pensamos que posiblemente es el primer poema dedicado al mismo; una vez que el retrato se populariza no es necesario describirlo detalladamente, porque el escritor da por hecho que su lector ya lo conoce). De estos elementos físicos infiere o imagina el escritor cualidades morales, sociales e históricas. También se caracteriza este poema por estar realizado siguiendo un orden vertical, de arriba abajo, de la cabeza a la espada. Posteriormente, lo habitual no será esto, sino acabar el poema focalizando la atención en la famosa mano sobre el pecho que dio título al retrato. El hecho de que el poema se cierre aludiendo a la espada (en lo que coincide con Guillermo Valencia), que además se empuña, en esta versión, también tiene su lógica, puesto que Zayas destaca en el personaje (un "hijodalgo" castellano) tanto un carácter ("impasible la faz, fiero el talante") como un destino ("espanto de las huestes de Calvino") propio de un soldado heroico en el 
campo de batalla. No hay alusiones a su posible espíritu atormentado o melancólico, como será habitual al describir al personaje, que en este poema es "de una pieza” y representa al hidalgo grave y adusto. La única nota que pudiera simbolizar cierta decadencia, en el personaje o en su momento histórico, es el primer verso del primer terceto: "Hay luz crepuscular en su semblante" (que podemos relacionar con "Es pálida su tez como la tarde" de Machado en "Felipe IV”), pero se sobreponen los elementos que sugieren un orgulloso carácter heroico.

Curiosamente, no es esta la única presencia del candiota en Retratos antiguos, pues el soneto que Zayas dedica a "Un caballero" de Tintoretto, que parece no excesivamente lejano al de la mano en el pecho, acaba con los siguientes versos, tras la descripción del personaje: "Símbolo audaz de un ánima espańola / en instante febril adivinada / por la sombría inspiración del Greco" ${ }^{12}$. El candiota admiró y aprendió de Tiziano y Tintoretto durante su estancia en Venecia, pero estos versos quizá simplemente se hacen eco de la idea de que fue el Greco quien mejor supo captar el alma de los caballeros espańoles, como seguramente sea el retratado ahora por Tintoretto y Zayas.

Francisco Villaespesa no dedicó un poema al caballero de la mano al pecho, pero, en su caracterización tópica, amable y triunfal del "Alma española" del Siglo de Oro (no muy lejana de la de Zayas) incluida en El jardín de las quimeras (1909), imaginó, en el séptimo soneto de la serie, que su propio yo lírico, si hubiera vivido hace tres siglos, sería un altivo soldado cristiano cuyas hazañas podrían haber sido inmortalizadas por el discípulo de Lope, y haber sido retratado por el candiota (que es caracterizado brevemente como un perturbado, al modo habitual en los siglos XVIII y XIX): “Tirso, mis aventuras rimaría, / y en el fondo espectral de su locura, / con la mano en el pecho, el Greco habría / copiado la altivez de mi figura"13.

Distinto es el soneto que dedica años después Manuel Machado a El caballero de la mano en el pecho, con este mismo título, que se publicó en Los lunes de El Imparcial en septiembre de 1910 como un adelanto del

12 Antonio de Zayas, ibidem, p. 55.

13 Francisco Villaespesa, “Alma española”, en El jardín de las quimeras. Poemas, VII, Barcelona, Editorial Atlante, s.f., pp. 127-128; José Álvarez Sierra, Francisco Villaespesa, Madrid, Editora Nacional, 1949, p. 170. 
libro Apolo. Teatro pictórico, de 1911, donde aparece junto a una lámina que reproduce fotográficamente, en tonos sepia, el lienzo (y a la que, en este caso, alude el deíctico inicial, "Este desconocido es un cristiano / de serio porte y negra vestidura") ${ }^{14}$. El volumen está dedicado a Francisco Giner de los Ríos, y el poema, a Manuel Bartolomé Cossío, que ya ha publicado su monografía sobre el pintor cretense. De esta forma, Machado reconoce la deuda y la filiación de su escritura con los profesores de la Institución Libre de Enseñanza y con la formación histórico-artística que allí recibió. El propio poeta señaló su propósito en una conferencia:

no se trata en este libro de simples transcripciones o descripciones ajustadas al original pictórico y que tengan como fin la simple evocación del cuadro. Yo he procurado la síntesis de los sentimientos de la época y del pintor, la significación y el estado del arte en cada momento, la evocación del espíritu de los tiempos. Y algo más, la sensación producida hoy en nosotros, insospechable para el autor. En una palabra yo pinto esos cuadros tal como se dan y con todo lo que evocan en mi espíritu; no como están en el Museo ${ }^{15}$.

El soneto se escribe en el momento de máximo apogeo del fervor de entresiglos por el Greco, y es sin duda la versión más destacada de la lectura que convirtió este retrato en paradigma del hidalgo castellano y de la sociedad de su tiempo, símbolo a su vez de una identidad nacional perdurable. Manuel Machado sancionó explícitamente esta lectura al escribir:

El Greco es, sin duda alguna, el más genuino y expresivo pintor de la España de su tiempo, de aquella España reconcentrada, furiosamente idealista, conquistadora en nombre de la fe, harapienta y grave, con los ojos puestos siempre en el cielo y tropezando a cada instante en la tierra, sin rendirse nunca. En este sentido y no el de su técnica discutidísima, he considerado yo al gran Teotocopuli, y escogido para mi Museo uno de sus retratos anónimos, el de El Caballero de la mano al pecho.

14 Los lunes de El Imparcial (12 de septiembre de 1910), p. 1; Apolo. Teatro pictórico, Madrid, V. Prieto y Compañía, Editores, 1911, pp. 63-64; en p. 61 hay una lámina, reproducción fotográfica del lienzo El caballero de la mano en el pecho.

15 Manuel Machado, "Génesis de un libro", en La guerra literaria (1898-1914), Madrid, Imprenta Hispano-Alemana, 1913, p. 44. 
[...] Lo que yo he tratado de sintetizar a través del cuadro, es el espíritu español de entonces y de siempre ${ }^{16}$.

El hecho de que el retrato pictórico ya se haya popularizado a la altura de 1910 (y de que, además, al soneto le acompañe una lámina del mismo), es razón suficiente para que, al contrario que ocurría con el poema de Zayas, ahora haya una máxima concentración. Su exposición es distinta; Machado describe el retrato según la importancia que concede a cada elemento del cuadro. De este modo, en el primer cuarteto aparece la "negra vestidura" y el brillo de la empuñadura de la espada; ambas bien definidas: la primera corresponde a un "cristiano", y la segunda a un "estoque toledano". El segundo cuarteto se dedica al rostro, en los que quizá son los mejores versos del soneto: "Severa faz de palidez de lirio / surge de la golilla escarolada, / por la luz interior iluminada / de un macilento y religioso cirio". Mediante una delicada metáfora lumínica, el poeta simboliza el carácter ascético y reconcentrado de su alma, que se asoma y refleja, podríamos decir, a través de la gola, en la palidez de su cara ("nadie como el Greco para dar a los rostros la expresión de la vida interior y del fuego del espíritu”, escribe Machado) ${ }^{17}$. Por ende, el lirio es una flor que en el modernismo simboliza un estado de ánimo, decadente o hiperestésico, de ensoñación y de anhelo del ideal. Ahora, con la rima "lirio / cirio", se sugiere un componente de delicadeza espiritual que se extiende a los dos tercetos del soneto, dedicados al elemento principal del cuadro, "la mano abierta sobre el pecho", que el poeta explica como gesto característico que refleja las cualidades morales del personaje, piadosas y nobles, y que, a modo de disciplina, afianza el amor de Dios frente a la posible tentación del amor mundano (lo que no está lejos de la recomendación de San Ignacio de Loyola en sus Ejercicios espirituales). La simplificación cromática del retrato, donde, en medio de la oscuridad, solo tres elementos aportan algo de luz (rostro, espada y mano), es algo que ha tenido muy en cuenta el poeta, quien ha aprovechado este aspecto de forma simbólica: la severidad y pobreza visual contribuye a establecer el carácter íntimo del personaje. Este ya no es un fiero soldado, como en el soneto de Zayas, sino un noble caballero de espíritu ascético, más en sintonía con los hidalgos de

16 Ibidem, pp. 54-55.

17 Ibidem, p. 54. 
Azorín. (No hará falta más que recordar los protagonistas de "Lo fatal” o "Una flauta en la noche", recogidos en Castilla. El protagonista del último relato citado se lleva repetidamente la mano al pecho, como también hacía el personaje antoniomachadiano del poema 81 de Soledades, "A un viejo y distinguido señor"; o como hará el de Vicente Aleixandre en "Las barandas", de Nacimiento último).

En 1911, Sofía Casanova dedica al caballero de la mano en el pecho la composición titulada "El caballero de la espada. Cuadro del Greco", una tirada de veintitrés serventesios alejandrinos incluida en su poemario más conocido, El cancionero de la dicha (1911), que cuenta con la presentación y el aval de distintos poetas que le dedican sus versos al inicio del libro, como Villaespesa, Ricardo León o Manuel Machado, entre otros. El poema, que ofrece una interpretación bastante convencional del personaje, al que atribuye las típicas acciones heroicas de un caballero aurosecular, en línea con el teatro de Marquina, no se interesa apenas por describir el cuadro (apenas lo hace en dos estrofas), sino por penetrar en el secreto del retratado, al cual interpela constantemente el sujeto lírico. Casanova entrecruza la convención del poema dedicado al cuadro del Greco con otros dos motivos fantásticos frecuentes en el modernismo, procedentes de relatos populares legendarios e infantiles: la del príncipe encantado y la del retratado que parece querer cobrar vida. Afirma que el caballero está apresado en el maleficio del cuadro, y que no puede escapar del mismo. Por eso recomienda a las muchachas bellas que rompan el conjuro con una "frase enigmática" o con un beso en su frente ${ }^{18}$.

En 1914, año del tricentenario del Greco, Francisco Maldonado dedica al caballero otro poema, también en serventesios, pero más breve que el de Sofía Casanova ${ }^{19}$. El texto se aleja de modelos parnasianos y apenas describe el cuadro. Del retratado solo señala, de forma sumaria, su mira-

18 Sofía Casanova, "El caballero de la espada. Cuadro del Greco", en El cancionero de la dicha, Madrid, R. Velasco, 1911, pp. 139-143.

19 Francisco Maldonado, "Cuadros del Greco. El caballero de la mano al pecho. A José González de Castro”, en Parnaso Español Contemporáneo. Antología completa de los mejores poetas especialmente seleccionada por José Brissa, ed. José Brissa, Barcelona, Casa Editorial Maucci, 1914, p. 274. Fue reproducido posteriormente en Marcos Rafael Blanco-Belmonte (dir.), El Greco. Homenaje de recordación y tributo de loa, Madrid, Ricardo Gansi, 1924, p. 64. 
da y su cabeza, para dedicar las estrofas finales a la espada y la mano, de forma que recuerda a la composición de Manuel Machado, pero sin la calidad lírica de este (la brillante segunda estrofa del soneto machadiano es torpemente imitada, atribuyendo ahora la "candela mística que alumbra" al caballero al "toledano acero" de la espada). El hecho de que el poeta no necesite describir el cuadro seguramente se debe a que lo considera ya conocido. A cambio, Maldonado dedica bastantes versos a construir una imagen tópica del hidalgo español valiente y cristiano que, en este caso, reparte sus afanes entre la conquista bélica, el apostolado de la cruz y el recuerdo de su dama. El personaje resulta bastante unidimensional, puesto que no hay rastro de la profundidad ascética ni de la vida anímica que Machado le había otorgado.

Fernando López Martín incluye dos sonetos alejandrinos en Sinfonías bárbaras (1915). El primero, que abre el poemario, es una alabanza tópica al artista, seguramente producto del tercer centenario del Greco. López Martín comienza su poema celebrando al Tajo y los muros de Toledo. Los tercetos se centran en el candiota, caracterizándolo como un caballero del Siglo de Oro según las convenciones modernistas. El último terceto lo dedica a otro motivo tópico finisecular: la fusión de su arte y de la esencia de la nación que lo acogió ${ }^{20}$. El segundo soneto levanta un poco más el vuelo, pero no aporta nada excesivamente valioso a la interpretación del mismo ni supera el modelo machadiano, al que parece seguir de cerca (compárense los cuartetos de uno y otro), con la variante de que, según esta lectura, la mano en el pecho se debe simplemente a una herida no del "amor divino", sino del "amor humano" ${ }^{21}$. Frente a la tercera persona descriptiva de casi todos los poemas anteriores, emplea, como Sofía Casanova, una segunda persona que apela directamente al personaje.

Al otro lado del Atlántico, el argentino Álvaro Melián Lafinur dedica al anónimo caballero uno de los mejores poemas de los que llevamos vistos, al menos por su empaque formal. "El caballero de la mano al pecho",

20 Fernando López Martín, "Un hidalgo", Sinfonías bárbaras. Versos de Fernando López Martín. Prólogo de Prudencio Iglesias Hermida, Madrid, Imprenta de Juan Pueyo, 1915, p. 47.

21 Fernando López Martín, "El caballero de la mano en el pecho (Cuadro del Greco)", ibídem, p. 36, y Por esos mundos, XVI, 244 (mayo de 1915), p. 494. 
incluido en Sonetos y triolets (1918) y pronto antologado por Borges ${ }^{22}$, se caracteriza por ofrecer una visión sobria, íntima y esencial del hidalgo, no muy lejana de la de Manuel Machado, pero con mayor indefinición. Del mismo solo destaca, en el primer cuarteto, el rostro y la mano, cuya posición quizá indique "un voto de lealtad". En el segundo, su figura y su mirada, en la cual el Greco, que aparece introducido en el poema, pintó "una tragedia silenciosa y afilada”. Son elementos físicos de quien es caracterizado de forma espiritual y ascética, y sobre cuyo misterio se hacen diversas suposiciones. La composición acaba mencionando el cuadro y la imagen representada, haciendo de este modo visible no solo al caballero, sino al pintor y a la obra pictórica, que interpreta como signo de aquellos tiempos, sobre el que el poema ha creado, a través de los adjetivos, una isotopía de alejamiento y decadencia, como si fuera una pátina de polvo temporal que aumenta el misterio sobre el significado del lienzo y su personaje.

Esther López Valencia, en su poemario Escorial (1922), incluye "El peregrino del amor", escrito "Ante el San Francisco de El Greco", según indica el subtítulo ${ }^{23}$. Es una canción lírica, de ritmo marcado y contenido neopopularista, en alabanza a San Francisco de Asís en un contexto pastoral. Realmente, este San Francisco a la italiana, "suavísimo cantor" amoroso que anda tiernamente por campos floridos, predicando a sus hermanos los animales, tiene muy poco tiene que ver con las representaciones pictóricas que del santo hizo el Greco convirtiéndolo en un espiritado fraile místico y castellano: a ninguno de sus lienzos se alude, ni siquiera a los dos que se conservan en El Escorial.

22 Álvaro Melián Lafinur, "El caballero de la mano en el pecho", en Sonetos y triolets, Buenos Aires, Mercatali, 1918, p. 23 <http://www.archive.org/stream/3383943\#page/ n23/mode/2up> (consulta 18 de abril de 2012); Jorge Luis Borges, "La lírica argentina contemporánea", Cosmópolis, 36 (diciembre de 1921); luego en Jorge Luis Borges, Textos recobrados. 1919-1929, Barcelona, Emecé, 2002, pp. 132-141 (p. 137). Véase por último Julio Noé (ed.), Antología de la poesía argentina moderna (1900-1925), Buenos Aires, Nosotros, 1926, pp. 355-356.

23 Esther López Valencia, "El peregrino del amor / Ante el San Francisco del Greco”, en Escorial, prólogo de Álvaro López Núñez, Madrid, Editorial Ibérica, 1922, pp. 75 79. El tópico del peregrinaje amoroso y de su dolorida canción, de rancio abolengo pero actualizado por el modernismo, aparece desde el comienzo del poemario. Pepa Merlo ha incluido a la autora en Peces en la tierra. Antología de mujeres poetas en torno a la Generación del 27, Sevilla, Fundación José Manuel Lara, 2010. 
Fernando Iglesias Figueroa, conocido imitador de Bécquer y autor de Sensaciones de Toledo (1933) y El Greco y otras sensaciones de Toledo (1935), aporta su homenaje a "El caballero de la mano al pecho" en 1924 con un poema homónimo en cinco serventesios alejandrinos ${ }^{24}$. Los tres primeros son deudores del soneto machadiano, y amplifican, como en una contradanza, el juego metafórico, lumínico y floral, que el anterior construyó en torno a la mano y al rostro, particularizado ahora en el misterio de su mirada. El cuarto serventesio contextualiza al personaje y al retrato citando a su autor y a la ciudad que le acogió, con una caracterización extendida desde el romanticismo; finalmente, la última estrofa concluye con una nueva interpretación histórica que fuerza lecturas anteriores: el caballero murió quemado en la hoguera a manos de la Santa Inquisición, "por el solo delito de pensar libremente". El poema acaba con un verso ("la inmortalidad puso un beso en tu frente") muy próximo a otro de Sofía Casanova en su poema dedicado a la pintura ("un beso que roce la calma de su frente"), aunque con un sentido distinto, porque ahora podemos entender que es el retrato del Greco quien otorga esa inmortalidad simbólica.

Guillermo Valencia dedica, en fecha incierta, dos sonetos de impecable factura al anónimo caballero retratado por el Greco. El primero, subtitulado "Idealidad", se caracteriza por hacer referencia, de forma más explícita que lo visto hasta el momento, a los valores pictóricos del retrato (íntegramente en su segunda estrofa), junto a la mención de los valores morales que representa el personaje (sobre todo, en los dos tercetos) ${ }^{25}$. En vez de imaginar una causa para el estado de ánimo que sugiere su rostro, el poeta constata que su serenidad melancólica es un enigma. Y en vez de cerrar el poema con la referencia a la mano, como Machado y sus imitadores, Valencia acaba con la mención a la espada, como había hecho Za-

24 Fernando Iglesias Figueroa, "El caballero de la mano al pecho", Los Lunes de El Imparcial (14 de septiembre de 1924), p. 10.

25 Guillermo Valencia, "Tríptico / El caballero desconocido / (Doménico Theotocópoulos pinxit.) / (Idealidad)", en Obra poética completa, p. 565. Véase Guillermo Valencia, Poesías y discursos, a cargo de Carlos García Prada, Madrid, Ediciones Iberoamericanas, 1959: "Tríptico" va fechado en 1937 (pp. 135-137). Valencia compone otro "Tríptico" de sonetos, hecho de écfrasis escultóricas ("I. La Estatua de Sal. II. La estatua de Ankiala. III. Refundición”), que en su Obra poética completa aparece justo delante del que comentamos. 
yas. De esta forma, mientras que los cuartetos establecen el misterio del personaje y sus valores pictóricos, respectivamente, los tercetos exaltan la calidad del hidalgo castellano como enseña nacional.

El segundo soneto, titulado "Al caballero del "Greco»", no es una descripción del lienzo, sino una apelación en segunda persona al anónimo hidalgo, donde se menciona, como en el poema de Iglesias Figueroa, a Toledo como marco natural, capaz de explicar al personaje y al pintor, y su propósito en el momento de realizar el retrato (los valores tópicos nacionales del hidalgo castellano). Además, las referencias deícticas en la primera y la última estrofa aluden al lugar donde el poeta observa el cuadro, una galería pictórica del "salón de la casa de Valencia", según el título de la sección donde aparece el poema ${ }^{26}$. Es decir, que el soneto destaca principalmente por la contextualización, a todos los niveles, del retrato, aquello que los poemas anteriores solían dar por supuesto o directamente obviaban.

También combinan la loa a la ciudad de Toledo y al pintor cuatro retóricos y altisonantes sonetos que Antonio de Zayas dedica al Greco en Epinicios. Segunda serie (1926, aunque los sonetos están fechados en 1914) ${ }^{27}$, que poco aportan a la imagen tópica del candiota como recreador del alma española, salvo una mayor insistencia en sus técnicas pictóricas junto a una visión imperial y cristiana de pintor y ciudad.

En estos ańos encontramos breves referencias al candiota en composiciones de otros autores. Así, Francisco Machado, hermano de los dos conocidos poetas, en su "Canto a Toledo", no deja de consignar "El Museo del Greco, su casa de reposo, / Y en la vecina iglesia, su magna producción”. El poema fue publicado en El Castellano el 28 de octubre de 1927 y luego incluido en sus Leyendas Toledanas (1929) ${ }^{28}$.

El Greco también aparece citado de forma significativa en un soneto de Pedro Luis de Gálvez que describe una pintura, pero no del creten-

26 Guillermo Valencia, "Sonetos a los antepasados y a otros retratos del salón de la casa de Valencia / Al caballero del "Greco"”, en Obra poética completa, p. 485.

27 Antonio de Zayas, "A Domenico Theotocópuli (El Greco)", en Epinicios. Segunda serie, Madrid, Lib. de Francisco Beltrán, 1926, pp. 108-111.

28 Francisco Machado, Leyendas Toledanas, Toledo, Imprenta de Sebastián Rodríguez, 1929. Véase asimismo Francisco Machado, El Reloj de la Cárcel. Poesías y Leyendas Toledanas de Francisco Machado, ed. Enrique Sánchez Lubián, Toledo, D. B. Ediciones, 2005, así como Daniel Pineda Novo, El otro Machado, Sevilla, Guadalquivir Ediciones, 2006. 
se, sino de uno de sus máximos seguidores, Ignacio Zuloaga. Se trata del Retrato de Enrique Larreta, el autor de La gloria de don Ramiro, donde el pintor vasco recrea, en el fondo del cuadro, una imagen de Ávila deudora de las visiones toledanas del Greco: "Sobre un cielo del Greco, cárdeno, anubarrado / el prodigioso hablista recorta la medalla / de su perfil romántico. Abajo, la muralla / de Ávila. El paisaje, seco y accidentado" 29 .

Lejos ya de este tipo de poema descriptivo, Unamuno dedica al pintor y a su retrato más famoso varias composiciones de su Cancionero en 1932. En "Toledo" (fechado a 21 de septiembre de 1928 y ampliado el 5 de abril de 1932), sugiere en dos estrofas una visión de la urbe como sueño espiritual, tenebroso, expresionista y de fríos colores, análoga a su óleo del Museo Metropolitano de Nueva York: Paisaje de Toledo ${ }^{30}$. Poco después, dedica al pintor y a su retrato más famoso otras dos breves composiciones, que fecha los días 4 y 5 de abril de 1932. En ellas vuelve a recordar, con algunos versos muy similares, los valores identitarios, tanto terrenales como artísticos y espirituales (gama cromática y luz), que definen al autor y su obra ("En el herrín y verdín y hollín del Greco / de Toledo, ceniza de verdad, / -tierra y cielo se roñan- dice el eco / “¡hágase luz!” en sempiternidad”). Destaca, además, la lucha de la carne y el espíritu en el caballero (hidalgo que encarna una realidad, una obra de arte, un alma y una tierra: "El hombre de la mano al pecho, / carne y sangre de luz terrena, / hidalgo del arte, es un hecho / con alma de espíritu llena”), en una nación y una historia que definen como labor la creación unamuniana y que, según afirma, concierne como tarea a todos españoles: "Le ata el cordón de Calatrava / contra la Castilla del Tajo, / vieja historia que nunca acaba / por ser nuestro eterno trabajo" 31 . El rector salmantino había escrito en 1914 un artículo en el que ofrecía su visión sobre el Greco, en línea con Cossío, Azorín y Baroja, resaltando la fusión del pintor con la tierra y los

29 Pedro Luis de Gálvez, "Cuadros de Zuloaga, 3, Larreta, en Ávila”, en Negro y Azul (1929), Granada, Comares, 1996, p. 97.

30 Miguel de Unamuno, "Toledo (Nueva redacción)", "Cancionero espiritual en la frontera del destierro", en Cancionero, en Obras completas, V. Cancionero. Poesías sueltas. Traducciones, ed. Ricardo Senabre, Madrid, Biblioteca Castro, 2002, p. 298.

31 Miguel de Unamuno, Cancionero, "De nuevo en España". III (1932), en Obras completas. $V$, pp. $766-767$. 
hombres que le rodearon, hasta el punto de convertirlo en el mejor reflejo de la espiritualidad espańola ${ }^{32}$.

El otro tipo de composición donde no falta el Greco en la poesía de entresiglos es aquel que se dedica a la ciudad de Toledo. Es frecuente en el modernismo encontrar poemas consagrados a las ciudades muertas, ciudades ensimismadas y silenciosas que han quedado al margen del progreso y la modernidad, asfixiadas por el peso de su tradición, de su historia y de su arte. En este ámbito, destacan las ciudades castellanas -junto a Granada-y, entre ellas, el Toledo potenciado por Baroja, Azorín o Barrès. El objetivo de estas composiciones, en sus mejores casos, suele ser la sugerencia de un estado de ánimo análogo al que produciría el paseo por la ańeja urbe escogida. Es frecuente el empleo para ello de distintos signos de sugestión evocadores y de referencias a sus espacios, obras de arte, personajes, leyendas o hechos históricos más definitorios. En el peor de los casos, el poema desemboca en un laudatorio catálogo de tópicos que casi podríamos calificar de "turísticos". En la mayoría de las ocasiones, el Greco aparece como un elemento más del "inventario" de Toledo, caracterizado de forma sumaria y convencional.

El primer ejemplo que selecciono pertenece nuevamente a Antonio de Zayas, quien en Paisajes, su poemario de 1903, se aleja del poema de tipo parnasiano con el que se le suele identificar y dedica varias composiciones a ciudades castellanas y andaluzas. Concretamente, la sección titulada "Vigilias" se compone de paseos nocturnos por distintas ciudades muertas. Ahí encontramos "Fantasía de Toledo", serie de cuartetos alejandrinos donde Zayas dedica varias estrofas a su legendario pasado visigodo antes de pasar a los Cigarrales de Tirso de Molina, el Cristo de la Vega de Zorrilla y el Toledo del Greco, en la figura de sus consabidos caballeros ${ }^{33}$.

32 Miguel de Unamuno, "El Greco", Rassegna d'Arte, XIV, 4 (1914), 75-85; fue incluido por Manuel García Blanco en el tomo VII de Miguel Unamuno, Obras completas, ed. Manuel García Blanco, Barcelona, Vergara, 1967; y en Miguel de Unamuno, En torno a las artes, Madrid, Espasa-Calpe, 1976, pp. 77-86. Véase Yasunari Kitaura, "Unamuno y el Greco", Revista de Ideas Estéticas, XXXV, 137 (1977), pp. 41-62, y "Unamuno ante Calderón y El Greco", Goya. Revista de arte, 161-162 (1981), pp. 340-345.

33 Antonio de Zayas, "Fantasía de Toledo", en Paisajes, Madrid, Imp. De A. Marzo, 1903, p. 169. 
Emilio Carrère es uno de los divulgadores de la mayoría de tópicos existentes en la poesía modernista. Que un motivo llegue a sus manos es síntoma de "normalización", de que ha sido empleado con abundancia y, por eso, es identificable para el lector. En su poema "La musa del río" recopilado en Dietario sentimental (1916) (e inspirado lejanamente en el "Nocturne parisien" de Verlaine), cuando le llega el turno al "Viejo puente de Alcántara sobre el Tajo”, el sujeto lírico exclama: “¡Oh puente toledana, en tu ojo negro y hueco / hay una eterna lágrima por la gloria ancestral; / tú viste la pupila visionaria del Greco / siguiendo la corriente del río musical!" 34 . El Greco es citado a beneficio de inventario, sin entrar en mayores averiguaciones, con uno de sus calificativos más frecuentes desde el siglo XIX ("visionario"), como un elemento que no puede faltar en el recuerdo de la ciudad.

No obstante, este tipo de versos demuestran algo significativo: el hecho de que citar al Greco en las primeras décadas del siglo XX no es una novedad ni un desafío, sino algo que se da por supuesto no ya solo en la recreación de Toledo, sino incluso en la más amplia reconstrucción de la identidad nacional. Valga como ejemplo el pésimo poema "La canción del deseo" de Felipe Sassone, escritor peruano que vivió casi toda su vida en España, donde, bajo el influjo de la "Divagación" dariana, se pasa revista a los consabidos tópicos castizos y a las glorias nacionales, sin que falte entre ellas el pintor cretense: "temblar viendo pintada la terrible tragedia / que tiene cada rostro en los cuadros del Greco" 35 .

De hecho, los poetas no se limitan a localizar los hidalgos del Greco en Toledo, puesto que, como sabemos, representan a los típicos caballeros españoles, que, como escribe Manuel Machado, "andan aún por estas calles"36. Así ocurre en los poetas que Onís calificó de "postmodernistas", es decir, cultivadores de un "modernismo refrenado" que se encamina hacia cierta sencillez lírica. Por ejemplo, Enrique Díez-Canedo, al recordar su niñez, sitúa a estos hidalgos paseando por el madrileño parque del Retiro en los autobiográficos "Versos íntimos" que abren su poemario $\mathrm{La}$

34 Emilio Carrère, "La musa del río”, en Dietario sentimental (1916), II, Madrid, Mundo Latino, s. f., pp. 63 y 65.

35 Felipe Sassone, "La canción del deseo", en Sus mejores versos, Madrid, Los Poetas, I, 16 (24 de noviembre de 1928), p. 27.

36 Manuel Machado, "Génesis de un libro", p. 55. 
sombra del ensueño $(1910)^{37}$. Y Fernando Fortún hace lo propio, situando al hidalgo actual "En tierra vasca", poema recogido en su libro póstumo Reliquias $(1914)^{38}$. Uno de los primeros sonetos de Dámaso Alonso se titula "El hidalgo", y, aunque no cita al Greco, es absolutamente deudor, incluidos ritmo, estructura e imágenes, de los poemas modernistas que hemos visto, sobre todo de Manuel Machado ${ }^{39}$. José del Río Sainz, en la segunda estrofa de su poema dedicado a "Santa Teresa de Jesús", también recuerda a los entecos hidalgos castellanos "retratados / en los Grecos" como una decantación de la historia y la esencia española, llena de tópicos elementos tradicionales y decadentes ${ }^{40}$.

Toledo sigue siendo parada obligada de viajeros, escritores y artistas (recordemos las excursiones de Buñuel, Lorca y Dalí, de las que hay testimonio fotográfico). Tanto el Greco como la ciudad sobreviven al tópico, y pocos escritores se sustraen al mismo. Así, José Moreno Villa inicia su poemario El pasajero (1914) con la sección homónima, donde su autor reconstruye líricamente su viaje por diversas localidades: Cuellar, Salamanca, Silos, y El Escorial, antes de llegar a Toledo. En la composición que dedica a esta destaca su experiencia personal, pero precisamente la parte quizá menos valiosa es aquella en que no puede evitar referirse a los tópicos sobre la ciudad (el cruce de culturas y religiones ya destacado, por ejemplo, por Cossío) y sobre el pintor (al que califica, a la manera tradicional, de "loco" que "veía alargado" ${ }^{41}$ ).

Gerardo Diego, en El romancero de la novia. Iniciales (1917, 1944), incluye un poema, "Fiebre otońal", en el que juega con este tópico modernista, uniendo de manera afortunada la sugerencia lumínica de los

37 Enrique Díez-Canedo, "Versos íntimos", El Liberal, 1, (11 de marzo de 1908), recogido en La sombra del ensueño, en Poesías, Granada, Comares, 2001, pp. 233-234.

38 Fernando Fortún, "En tierra vasca", Reliquias, Madrid, Imprenta Clásica Española, 1914, pp. 25-26 (p. 26).

39 Dámaso Alonso, "Del camino castellano / El hidalgo / (1914)", Nueva Etapa, 191 (1918), en Poesía y otros textos literarios, Madrid, Gredos, 1998, p. 29.

40 José del Río Sainz, "Santa Teresa de Jesús", Versos del mar y otros poemas, en Poesía, ed. Luis Alberto de Cuenca y José del Río Mons, Granada, Editorial Comares ("La Veleta"), 2000, p. 320.

41 José Moreno Villa, "Toledo (Muchos días)”, El pasajero, 1914, sección "El pasajero”, Poesías completas, ed. Juan Pérez de Ayala, México / Madrid, El Colegio de México / Residencia de Estudiantes, 1998, pp. 141-142. 
paisajes toledanos del Greco con una rima fácil, esdrújula y de derribo, pero muy apropiada ("Doménico" / "helénico"), próxima a las de Manuel Machado en El mal poema ${ }^{42}$.

La única manera de enfrentarse con cierto éxito a esta visión es mediante una recreación irónica y crítica de la misma, y es lo que intenta Oliverio Girondo en su poema "Toledo", incluido en Calcomanías (1925), y por Federico de Onís en su famosa Antología, del que selecciono los versos dedicados al Greco, en los que se exageran y entremezclan rasgos pictóricos e históricos sobre el antaño glorioso hidalgo español, en lo que ahora es una ciudad muerta pesadillesca: "Perros que se pasean de golilla / Con los ojos pintados por el Greco. / [...] / Hidalgos que se alimentan de piedras y de orgullo, / tienen la carne idéntica a la cera de los exvotos / y un tufo a herrumbre y a ratón" ${ }^{43}$.

La referencia al Greco es prácticamente inevitable en toda la poesía dedicada en a la ciudad imperial. Gastón Baquero cita su pintura más famosa en "Amapolas en el camino de Toledo", de Memorial de un testigo (1966): "Yo he visto todo eso: yo, ciego, he visto más: / la alondra saboreando el amargor del incienso, / la borla caída de un sepulcro gótico, / el cirio rojo en la tumba del cardenal, / la mariposa comunicando un secreto a San Cristóbal, / la osamenta de un rabino escondida bajo la armadura del Conde de Orgaz" ${ }^{4}$. Y poco después, Jorge Guillén homenajea al Greco uniéndolo para siempre a su ciudad, pero tratando de sustituir una mirada tópica y convencional por otra que destaca la unión del espacio

42 Gerardo Diego, "Fiebre otoñal", en El romancero de la novia. Iniciales (1917; Madrid, Hispánica, 1944), en Obras completas. Poesía I, ed. Francisco Javier Díez de Revenga, Madrid, Alfaguara, 1989, p. 50. Diego vuelve a nombrar al Greco en "Scherzo cromático", de La luna en el desierto y otros poemas (1949) e, incidentalmente, en "La doncella de Judit", de Versos divinos (1970) y en "Antonio Buero Vallejo", de Carmen jubilar (1975).

43 Oliverio Girondo, "Toledo", en Calcomanias, (Calcomanias. [Veinte poemas para ser leidos en el tranvía. Calcomanías. Espantapájaros] Poesía reunida 1923-1932, Sevilla, Renacimiento, 2007, p. 78); recogido en Antología de la poesía española e hispanoamericana (1882-1932), ed. Federico de Onís, Madrid, Centro de Estudios Históricos, 1934, pp. 994-995 (fechado "Abril, 1923").

44 Gastón Baquero, "Amapolas en el camino de Toledo", en Memorial de un testigo (1966), en Poesías completas (1935-1994), ed. Alfonso Ortega Carmona y Alfredo Pérez Alencart, Madrid, Fundación Central Hispano, 1995, pp. 117-118 (p. 118). 
toledano con los valores pictóricos del candiota, en la que quizá es la mejor versión de este tipo de poema ${ }^{45}$.

Tanto Vicente Aleixandre como León Felipe, en los años sesenta, ofrecen interpretaciones líricas sobre el noble hidalgo español que aún podemos considerar deudoras de las lecturas que establecieron Azorín o Cossío. Aleixandre -sin referirse específicamente al Greco-, en el poema "Quinto par", I, que pertenece a la sección "Retratos anónimos" de En un vasto dominio (1962); León Felipe, en el titulado "El español desconocido. Pie... para aquel cuadro de El Greco que algunos han llamado: 'Retrato de un caballero anónimo"', incluido en ;Oh, este viejo y roto violín! (1965), donde escribe: "Lo que quiero decir es esto: / que este retrato es... un milagro. / Aquí está pintada, / escuetamente, / una sustancia española, / algo que hubo una vez en "aquella tierra" / y que nunca se ha vuelto a producir" [...] "este desconocido era nada menos que / LA GRAN ESPAÑA"46.

En el ámbito del modernismo tardío e intimista se encuadra Los poemas cotidianos de Max Aub, publicado en 1925 con prólogo, precisamente, de Enrique Díez-Canedo. En el poemario encontramos una composición, de la serie "Las tardes", la novena, que recrea el tópico modernista (emparentando con Bécquer) de la estancia silenciosa y solitaria, llena de signos de sugestión que hacen percibir el alma de las cosas. Allí, las luces y sombras que producen el crepitar del fuego del hogar crean, en los versos de Aub, un efecto lumínico donde la pintura del Greco (concretamente, su Pentecostés) es usada de forma más original, en una comparación bastante afortunada: "Los muebles oscuros / puéblanse de lacas, / espejos de llamas / rojas y amarillas, / parécenme almas / negras, atormentadas, / que hacen memorar / luces de Pentecostés / que el Greco hizo volar”7.

Finalmente, los versos anteriormente citados de Oliverio Girondo nos acercan a otra lectura modernista del Greco quizá menos frecuente, la que

45 Jorge Guillén, "El Greco", en Homenaje. Reunión de vidas, 6. Fin. Convivencia (Aire nuestro. Homenaje, Barcelona, Barral Editores, 1978, p. 566).

46 León Felipe, "El espańol desconocido. Pie... para aquel cuadro de El Greco que algunos han llamado: «Retrato de un caballero anónimo»: ;Oh, este viejo y roto violin?", en Poesias completas, Madrid, Visor, 2004, pp. $782-787$ (pp. 784 y 787).

47 Max Aub, "Las tardes", poema 9, Los poemas cotidianos / con un prólogo de Enrique Díez Canedo, Barcelona, s. e., 1925, pp. 68-69. 
podemos denominar feista o grotesca ${ }^{48}$, dentro de una vía que manifiesta una visión decadente y expresionista de la llamada "España negra", atraída por lo mórbido y misterioso de una España religiosa y trágica (cementerios, procesiones de Semana Santa, Cristos lívidos, aquelarres de brujas, miserables y mendigos, los toros y el flamenquismo, etc.), presente en la pintura, sobre todo, de Regoyos, Gutiérrez Solana y Zuloaga, como ya señalaba Moreno Villa ${ }^{49}$. En este caso, el candiota aparece como un personaje oscuro, relacionado en ocasiones con saberes nigrománticos (no en balde, habitó en Toledo una casa construida en el solar donde estaba el palacio del marqués de Villena), como ya apuntaba implícitamente, por ejemplo, el poema que hemos visto de Sofía Casanova.

Tenemos ejemplos que van desde los más convencionales, como el de Emilio Carrère en "El campanario de las brujas", de Dietario sentimental (1916, donde escribe, refiriéndose a estas: "Son amigas de Goya, son amigas del Greco, / y aunque anidan en nuestro corazón visionario, / la conseja nos dice que viven en el hueco / del viejo campanario") ${ }^{50}$, a los casos más elaborados, dentro de un modernismo irónico y expresionista, trágico-humorístico, como el que practica con materiales de derribo Ramón del Valle-Inclán en "El crimen de Medinica", de La pipa de kif (1919): "Crimen horrible pregona el ciego / y el cuadro muestra de un pintor lego, / que acaso hubiera placido al Griego. / [...] / Azul de Prusia son las figuras / y de albayalde las cataduras / de los ladrones. Goyas a oscuras" 51 .

Recordemos que en el prólogo del esperpento de Los cuernos de don Friolera (1921), el lienzo que descubre don Manolito en las ferias de Santiago el Verde, y que, como es sabido, da pie a una discusión programática sobre lo que es el esperpento, es también “¡Un cuadro muy malo, con la

48 Véase El feísmo modernista (Antología), ed. Pedro J. de la Peña, Madrid, Hiperión, 1989; y, Poesía bohemia española. Antología de temas y figuras, ed. Víctor Fuentes, Madrid, Celeste Ediciones, 1999.

49 José Moreno Villa, "Pandemonio", España, 268 (1920), p. 11.

50 Emilio Carrère, "El campanario de las brujas", Dietario sentimental (1916), p. 111; en Sus mejores versos, Madrid, Los Poetas, 1928, p. 42, vv. 37-40.

51 Ramón del Valle-Inclán, "Clav. XIV. El crimen de Medinica. 8", La pipa de Kif, en Claves líricas. Versos de don Ramón del Valle-Inclán. Opera Omnia, Madrid, Companía Ibero-Americana de Publicaciones, 1930, IX, pp. 231-232, vv. 1-3 y 13-15. 
emoción de Goya y del Greco!”52. Es evidente que a Valle-Inclán le interesa relacionar su teoría del esperpento con las deformadas y alargadas figuras humanas del cretense, que ya habían sido tomadas, precisamente, con antecedentes del expresionismo. No obstante, este tipo de feismo se relaciona con más frecuencia, desde el romanticismo, con las pinturas negras y los grabados de Goya que con los lienzos del Greco (aunque, como estamos viendo, también es habitual, desde el siglo XIX, emparejarlos, "haciendo alusión a los mismos rasgos definitorios: el capricho, la búsqueda de la originalidad a ultranza, el haberse formado una 'escuela especial suya'. En definitiva: la extravagancia y el poco respeto a las reglas, pero también la sospecha de genialidad") ${ }^{53}$. Un colofón muy posterior de esta visión tremendista (además, en su variante nigromántica) será "La noche de Doménico Theotocopulis”, del cubano Félix Pita Rodríguez ${ }^{54}$.

\title{
Anexo
}

Salvador Rueda, "La Paleta (Con motivo del baile del Círculo de Bellas Artes)", 1895:

\author{
¡Oh paleta! ¡Oh diccionario \\ que entienden todos los pueblos!; \\ [...] \\ Según quien supo tu idioma, \\ fuiste vario en tus aspectos; \\ en Murillo, has sido místico, \\ en Velázquez, noble y regio, \\ franco y sublime en Rosales;
}

52 Ramón del Valle-Inclán, Martes de Carnaval. Esperpentos, ed. Ricardo Senabre, Madrid, Espasa-Calpe, 1988, p. 65.

53 José Álvarez Lopera, op. cit., p. 15, quien cita un primer paralelismo entre las "bizarres peintures du Greco" y las "caricatures de Goya" en un artículo aparecido en el Courier Français de París en febrero de 1838; también el Barón Taylor los compara en su Voyage pittoresque en Espagne, París, 1826-1860, pp. 115-116.

54 Félix Pita Rodríguez, "La noche de Doménico Theotocopulis", en Las Noches, La Habana, Editorial La Tertulia, 1964; Antología de la poesía cósmica de Félix Pita Rodriguez, México, Frente de Afirmación Hispanista, 1999, pp. 66-67. 
enigmático en El Greco, en Miguel Ángel grandioso, y en el gran Fortuny espléndido. ¡Oh paleta! ¡Oh breve mundo! ${ }^{55}$

Antonio de Zayas, "Domenico Theotocópuli. El inquisidor”, Retratos antiguos, 1902:

Los graves ojos que levanta al cielo emblema son de inquisidor destino; tiene recta nariz, rostro cetrino, áspera barba y reluciente pelo.

Nació hijodalgo en castellano suelo y, espanto de las huestes de Calvino, luce rico joyel adamantino sobre negro jubón de terciopelo.

Hay luz crepuscular en su semblante, es gris el leve encaje de su gola y gris la mano que en el pecho extiende;

e impasible la faz, fiero el talante, con la siniestra empuña la española, fúlgida espada que del cinto pende ${ }^{56}$.

Francisco Villaespesa, "Alma española”, VII, El jardín de las quimeras. Poemas, 1909:

Avivar con mis manos los tizones del hogar, y a mis hijos, en mi tierra, entre pausas de asma y oraciones,

55 Salvador Rueda, "La Paleta (Con motivo del baile del Círculo de Bellas Artes)", La Gran Vía, 87 (24 de febrero de 1895). José Álvarez Lopera, op. cit., p. 521, señala una publicación posterior en Álbum Salón, Barcelona, III, 43 (1 de junio de 1899), p. 136.

56 Antonio de Zayas, "Domenico Theotocópuli. El inquisidor", en Retratos Antiguos, Madrid, Establecimiento Tipográfico de A. Marzo, 1902, p. 83. 
narrar lances de amor, fortuna y guerra.

Tirso, mis aventuras rimaría, y en el fondo espectral de su locura, con la mano en el pecho, el Greco habría copiado la altivez de mi figura. Todas las tardes a la iglesia iría para ahogar mis pecados en la eterna católica piedad que a Cristo loa, y ya noche, a mi casa tornaría, arrastrando el reúma de mi pierna, igual que el buen don Lope Figueroa ${ }^{57}$.

Manuel Machado, "El caballero de la mano en el pecho", 1910, Apolo. Teatro pictórico, 1911:

Este desconocido es un cristiano de serio porte y negra vestidura, donde brilla no más la empuñadura de su admirable estoque toledano.

Severa faz de palidez de lirio surge de la golilla escarolada, por la luz interior iluminada de un macilento y religioso cirio.

Aunque sólo de Dios temores sabe, porque el vitando hervor no le apasione, del mundano placer perecedero,

en un gesto piadoso, y noble, y grave, la mano abierta sobre el pecho pone, como una disciplina, el caballero ${ }^{58}$.

57 Francisco Villaespesa, "Alma española”, VII, en El jardín de las quimeras. Poemas, Barcelona, Editorial Atlante, 1909, pp. 127-128; José Álvarez Sierra, Francisco Villaespesa, p. 170.

58 Manuel Machado, "El caballero de la mano en el pecho", Los lunes de El Imparcial (12 de septiembre de 1910), p. 1. En Manuel Machado, Apolo. Teatro pictórico, Madrid, V. Prieto y Compañía, Editores, 1911, pp. $63-64$ (p. 61), hay una lámina, 
Sofía Casanova, "El caballero de la espada. Cuadro del Greco", El cancionero de la dicha, 1911:

Y juraslo, la mano sobre el pecho valiente, pronta -si a dudar llego- por la cruz de la espada, que tu historia no es esa que divulga la gente rufianesca, una historia como pocas menguada.

Enfloreciste -afirmas- timbres de tu linaje, que del Rey confidente fuiste por cortesano, que al Santo Oficio un tiempo rendiste vasallaje cual corresponde a un noble piadoso castellano.

Que de Dios en defensa tus manos se tiñeron con sangre de los moros y judíos serviles... que tus labios prudentes si un secreto vendieron, fue de Dios en provecho destruyendo a los viles...

delación no se nombra la verdad proclamada, quemar a los herejes es deber, no mancilla, solo cuando sus huesos blanqueen la llanada, del Cid y de nosotros será digna Castilla.

Así dice en la estancia difusa y silenciosa, la voz queda, sin tonos, del bello personaje de la erguida cabeza, y la barba sedosa en la gola que afina negruras del ropaje.

Y la mano que afirma lealtad y proezas, temblor tiene de ataque, de terror o partida... la lividez del rostro pérfida sutileza, y la mirada tiene serenidad fingida.

¿Quién eres? Te pregunto con ansiedad, atado mi espíritu al misterio de tu frente inmutable, dilo, aunque la certeza no vale lo ignorado, ni hay atracción más fuerte que la de lo insondable.

reproducción fotográfica del lienzo El caballero de la mano en el pecho. 
Y yo vengo movida por extraño conjuro a saber lo que hiciste, a saber cómo fueres, a adorar tu hidalguía si no fuiste perjuro, a execrarte, si hiciste llorar a las mujeres.

Nadie sabe tu historia, nadie donde naciste, si te honraron por justo, si has sufrido destierro: en Toledo la sacra, ¿`cuántos años viviste? ¿Del de Orgaz no recuerdas el histórico entierro?

Tu secreto me has dicho; ya conozco tu historia, gran señor toledano, mal herido de amores... cruel has sido y valiente, y a tus días de gloria no les falta grandeza, pues les sobran dolores.

El Greco en una hora de poder sobrehumano echó a tus nobles plantas la red del maleficio, y hechizado, me miras mi triste castellano, y esperas que te salve de tu horrendo suplicio.

Más de dos siglos hace que te quejas sin queja, que el temblor de tu mano es esfuerzo inaudito por romper tus prisiones, y algente te deja prisionero en un cuadro prodigioso y maldito.

Se retuerce abrasado mi espíritu por darte libertad, vida, y siento mi impotencia de muerte... ¿Qué frase es la que tiene el poder de salvarte? ¿Qué acto puede a la vida redivivo volverte?

Beldades juveniles que adoráis la leyenda de aquel Príncipe rubio por amor encantado en la copa de un pino, o en la oscura vivienda de una bruja muy blanca que lo tiene embrujado,

venid al caballero que ha hechizado un artista y romped el conjuro que lo oprime inclemente, 
con la frase enigmática que os inspire su vista. con un beso que roce la calma de su frente.

Que sus ojos perciban la boca que lo nombra, que sean vuestras frases emoción y fragancia, que alguien diga: imposible, y aureolando la sombra un acento se escuche que murmure: constancia.

Que el aroma de rosas, cual incienso de ofrenda, le corone las sienes, le acaricie la mano, y trazad en el aire, cual dice la leyenda, dos cruces con la rama de un almendro temprano.

Cada cual de nosotros el poder atesora de romper cautiverios, de salvar corazones, de despertar el sueño que en otras almas mora, de dar alas y ritmo de vida a las ficciones.

Y todo lo podemos, si solo el bien ansiamos; la vida ante nosotros ensanchará el camino si, para conquistarla, conscientes avanzamos con las únicas armas que vencen el destino.

El amor que perdona, la intuición que guía, la pasión en acecho, mas el pecho encalmado... la voluntad vibrante y atenta la alegría en el presente oyendo sentencias del pasado.

Beldades juveniles: oíd atentamente de vuestros corazones el murmullo sagrado, y la fórmula mágica hallaréis que potente libre de sus prisiones al príncipe encantado.

Pulsad del sentimiento la lira intensa y varia, y cercad con un canto de amor al caballero que una vez, en un lance de gloria legendaria rompió ante su enemigo, por no herirle, el acero...

Se retuerce abrasado mi espíritu por darte 
caballero sin tacha, la vida de tu muerte...

¿Qué frase es la que tiene el poder de salvarte?

¿Qué acto puede a la vida redivivo, volverte? 59

Francisco Maldonado, "Cuadros del Greco. El caballero de la mano al pecho”, en Parnaso Español Contemporáneo, 1914:

Es sobrio, es agresivo su talante;

va con afán la alucinada vista

a lo infinito, y pasa el mar de Atlante

en son de apostolado y de conquista.

Acaso allende el mar, henchidas de oro,

ve las islas plañidas del Profeta:

manda su corazón tras el tesoro

y sobre él una cruz enverga escueta.

La liviana cabeza lleva erguida, que jamás razonó en plazas y reales: - ¿Para qué? - acabará por ser vencida siempre, a vueltas de prestes y curiales.

Distrae apenas del heroico empeño

la obsesionada y ciega fantasía por evocar la dama del ensueño, y una Salve rezar o Ave María.

A guisa de venera se columbra, pendiendo al pecho el toledano acero, como candela mística que alumbra del Espíritu Santo a un caballero.

Y la mano de hidalgo castellano -en riscado ademán- franca, valiente, la loca mano, la indomable mano, se lleva al corazón y no a la frente $e^{60}$.

Fernando López Martín, "El Greco”, Sinfonias bárbaras, 1915:

59 Sofía Casanova, "El caballero de la espada. Cuadro del Greco", en El cancionero de la dicha, pp. 139-143.

60 Francisco Maldonado, "Cuadros del Greco. El caballero de la mano al pecho. A José González de Castro”, en Parnaso Español Contemporáneo, p. 274. Fue reproducido posteriormente en Marcos Rafael Blanco-Belmonte (dir.), op. cit., p. 64. 
Del Tajo caudaloso los rápidos torrentes que bañan de Toledo los pardos murallones, de príncipes gloriosos las altas tradiciones murmuran a la sombra de caducales puentes.

Y dicen que en el grato rumor de las corrientes, rumor que el dejo imita de las viejas oraciones, a un príncipe se llora, venido de regiones donde del Arte fueron las cristalinas fuentes.

Señor que nunca el firme valor de su tizona gastó en tejer los lauros de su imperial persona, sombría en el vestido y en perfil hispana,

bastóle para ello fundir en los crisoles de su paleta mágica las tierras y los soles de la vetusta y sobria llanura castellana ${ }^{61}$.

Fernando López Martín, "El caballero de la mano en el pecho (Cuadro del Greco)", Sinfonias bárbaras, 1915:

Señor: de vuestro nombre la cifra es ignorada; pero en el limpio y firme mirar de vuestros ojos se muestra claramente que nunca los sonrojos de los villanos hechos tińeron vuestra espada.

En el cetrino rasgo de vuestra faz ascética; que adorna el albo lino de una sutil gorguera, se asoma vuestro espíritu como encendida hoguera que ardiese bajo el soplo de una visión profética.

Y hastiado de los goces que da el amor divino, para beber de todas las mieles del camino, quisisteis ser herido por el amor humano.

61 Fernando López Martín, "El Greco", Sinfonías bárbaras. Versos de Fernando López Martín, Madrid, Imprenta de Juan Pueyo, 1915, p. 11. 
Por eso, y porque el alma se os iba con la vida, pusisteis sobre el pecho, para tapar la herida, la pálida azucena de vuestra noble mano ${ }^{62}$.

Álvaro Melián Lafinur, "El caballero de la mano en el pecho”, Sonetos y triolets, 1918:

Surge el rostro viril de la redonda

Golilla señorial. Al pecho alzada,

La mano marfileńa y afilada

Tal vez a un voto de lealtad responda.

Dijérase que ya la muerte ronda

En torno a su figura descarnada.

Pintó el Greco en su extática mirada

Una tragedia silenciosa y honda.

¡Ah, quién sabe en qué místico martirio

En qué extrahumano amor, en qué delirio

De gloria ardió su corazón estoico!

Eternizado así en la tela antigua

Es una imagen pálida y exigua

De su siglo fanático y heroico ${ }^{63}$.

Esther López Valencia, "El peregrino del amor”, Escorial, 1922:

\section{Ante el San Francisco del Greco.}

De los montes de la Alvernia descendía el Peregrino,

En sus manos y en su pecho las heridas del Amor

En la estela luminosa que dejaba en el camino

Aún vibraban los gemidos del suavísimo cantor:

$$
\text { iAy dolor, }
$$

Que no es amado el Amor!

Florecían en sus manos maravillas de leyenda

Y en sus labios florecían las palabras del amor.

62 Ibidem, p. 36, y Fernando López Martín, Por esos mundos, XVI, 244 (1915), p. 494.

63 Álvaro Melián Lafinur, "El caballero de la mano en el pecho", en Sonetos y triolets, Buenos Aires, Mercatali, 1918, p. 23. 
Las hermanas golondrinas se agrupaban en la senda

Escuchando los concentos del suavísimo cantor:

iAy dolor,

Que no es amado el Amor!

Y las blancas ovejuelas olvidando sus apriscos

Le seguían mansamente, mensajeras del amor;

Y las fieras de los bosques y los lobos de los riscos

Acudían al conjuro del suavísimo cantor:

$$
\begin{gathered}
\text { ¿Ay dolor, } \\
\text { Que no es amado el Amor! }
\end{gathered}
$$

A su paso los arroyos suspiraban dulcemente,

Murmurando quejumbrosos el poema del amor;

Y, rodando entre las flores, repetían quedamente

Las seráficas canciones del suavísimo cantor:

iAy dolor,

Que no es amado el Amor!

Y los cielos y la tierra suspendidos y admirados

Escucharon por doquiera las palabras del amor;

Los furiosos huracanes y los céfiros alados

Repitieron los suspiros del suavísimo cantor:

iAy dolor,

Que no es amado el Amor!

El amor era su centro, el amor era su nido,

Y abrasó la tierra toda en el fuego del Amor...

¡Y aún resuenan, aún resuenan en el mundo corrompido

Las cantigas celestiales del suavísimo cantor:

iAy dolor,

Que no es amado el Amor!

¡Ay dolor! ${ }^{64}$

Fernando Iglesias Figueroa, "El caballero de la mano al pecho", 1924:

64 Esther López Valencia, "El peregrino del amor”, en Escorial, Madrid, Editorial Ibérica, 1922, pp. 75-79. 
En el pecho descansa, como un lirio, la mano, una mano afilada, pulida, marfileña; hay un sereno gesto en su rostro alargado; una vaga inquietud en sus pupilas sueña.

Desde el oscuro fondo del cuadro, su mirada ve desfilar la vida, serena e impasible, y refulge el marfil de su mano alargada como una blanca flor de un jardín imposible.

Una gran flor simbólica, eso es tu blanca mano, símbolo de altivez, de pureza, de paz, y brillan las inquietas llamas de tu[s] pupilas en el místico marco de tu pálida faz.

Te dio vida el pincel visionario del Greco; Toledo conoció tus negras vestiduras, y de tu grave voz aun conservan el eco sus rúas solitarias, silenciosas y oscuras.

Te consumió en su hoguera la santa Inquisición por el solo delito de pensar libremente; tu boca tuvo un gesto de desdén... y perdón, y la inmortalidad puso un beso en tu frente ${ }^{65}$.

Guillermo Valencia, "El caballero desconocido / D. Theotocópulos / (Idealidad)":

Púdica sombra enmarca la faz oval y austera en la serenidad de su melancolía ¿Qué velará esa frente? ¿Quién descifrar podría ese tinte fugaz de otoño en primavera?

Negro ropaje viste su plenitud procera. Y como tenue lumbre que vierte la hidalguía, turban tres notas blancas la parda sinfonía:

65 Fernando Iglesias Figueroa, "El caballero de la mano al pecho", Los Lunes de El Imparcial (14 de septiembre de 1924), p. 10. 
los encajes del puño, la mano y la gorguera.

Nútrese del silencio que al mérito corona.

Proezas, glorias, estirpe son ritmo que eslabona

pulcritud y constancia, fe, lealtad y decoro.

Si conciencia es orgullo, y es voluntad grandeza

en noble señorío del pecho a la cabeza,

¡bien va sobre un estoque la brillantez del oro ${ }^{66}$ !

\section{Guillermo Valencia, "Al caballero del «Greco»":}

Quédate aquí, señor desconocido, presidiendo el concurso de tus pares;

vienen todos de heráldicos solares

que hay en la tierra de donde has venido.

En el Toledo lóbrego y roído

de las flexibles hojas tutelares,

al amor de sus fieros valladares,

la flor de esta mansión armó su nido.

Domenico Teocópulos, un día,

quiso en tu faz pintarnos la hidalguía,

la bondad, la entereza y el decoro...

En medio de estas sombras del pasado, eres, oh prócer, su trasunto alado con tu alma pulcra y tu espadín de oro ${ }^{67}$.

Antonio de Zayas, "A Domenico Theotocópuli (El Greco)", Epinicios. Segunda serie, 1926:

66 Guillermo Valencia, "Tríptico / El caballero desconocido / (Doménico Theotocópoulos pinxit.) / (Idealidad)", en Obra poética completa, Madrid, Aguilar, 1955, p. 565. Al final del "Tríptico" consta: "Abril, 1938” (p. 566). Véase Guillermo Valencia, Poesías y discursos, pp. 135-137: "Tríptico" va fechado en 1937.

67 Guillermo Valencia, "Sonetos a los antepasados y a otros retratos del salón de la casa de Valencia / Al caballero del 'Greco'”, en Obra poética completa, p. 485. 
¡Salve, insigne ciudad, patria adoptiva del portentoso vástago de Creta que somete al poder de su paleta del linaje español el alma viva!

Tú, insomnes ojos de mirada altiva; Tú, amarillentos pómulos de asceta, en negro fondo de mansión escueta, alumbrada por lágrimas de oliva, ofreces como espléndido tesoro, ya en el ocaso de la Edad de Oro del sorprendente imperio castellano,

al que con grises de penumbra ingrata vence el azul y humilla la escarlata de los ducales lienzos del Tiziano ${ }^{68}$.

II

Él, con verdores de arrayán de Grecia, teje el manto de pálida matrona y pone en torno de su sien corona, escándalo quizás de turba necia.

Él con pupila perspicaz deprecia, o con rebelde audacia desentona el ocre del Cagliari de Verona y el carmín del Robusti de Venecia.

Él, revolviendo con indócil mano sombras de noche y claridad de día para gloria y honor del pueblo hispano,

68 Antonio de Zayas, "A Domenico Theotocópuli (El Greco)”, en Epinicios. Segunda serie, Madrid, Lib. de Francisco Beltrán, 1926, p. 108. 
graba la fe de las tenaces gentes que llevaron la Excelsa Eucaristía a redimir ignotos continentes ${ }^{69}$.

Y epilépticos santos, confesores revestidos de lívidas estolas, rostros convulsos, raras aureolas que irradian arbitrarios resplandores.

De macilenta faz inquisidores, ahogados por los rizos de las golas; altaneras figuras españolas saturadas de místicos fervores,

Él agrupa de Orgaz en el sepelio, agolpa de Jesús en el espolio, ordena en pos del mílite Mauricio.

¡Y su pincel comenta el Evangelio, aguza la piedad, exalta el solio, glosa el amor, acendra el sacrificio! ${ }^{10}$

IV

¡Salve, Corte Imperial; salve, Toledo, augusto emporio por el Tajo cinto, de la columna de las artes plinto, que la fama señala con el dedo!

En ti palpita el corazón sin miedo de la Espańa inmortal de Carlos Quinto, y el gigante pintor del "Laberinto" templa en tus calles su mental denuedo.

69 Ibidem, p. 109.

70 Ibidem, p. 110. 
¡Tú de sus ojos el cristal hechizas, tú de su genio el resplandor te abrogas al arcaico tañer de tus campanas,

y amorosa recoges sus cenizas, al par que tus vetustas sinagogas el rumor de las vísperas cristianas!

Toledo, 7 de abril de $1914^{71}$.

\section{Miguel de Unamuno, Cancionero:}

En el herrín y verdín y hollín del Greco

de Toledo, ceniza de verdad,

-tierra y cielo se roñan- dice el eco

“¡hágase luz!" en sempiternidad.

4 de abril, 1932 .

El hombre de la mano al pecho, carne y sangre de luz terrena, hidalgo del arte, es un hecho con alma de espíritu llena. Le ata el cordón de Calatrava contra la Castilla del Tajo, vieja historia que nunca acaba por ser nuestro eterno trabajo.

5 de abril, $1932^{72}$.

71 Ibidem, p. 111.

72 Miguel de Unamuno, Cancionero, "De nuevo en España" III (1932), en Obras completas, V. Cancionero, pp. 766-767. 